International Journal of Engineering Applied Sciences and Technology, 2020

Vol. 4, Issue 9, ISSN No. 2455-2143, Pages 186-193

Published Online January 2020 in IJEAST (http://www.ijeast.com)

\title{
ENVIRONMENTAL EFFECTS ON ACTIVATED CARBON REINFORCED POLYMER COMPOSITE
}

Vivek. D

Department of Aerospace Engineering

Alliance College of Engineering and Design

Alliance University

Bangalore, Karnataka, INDIA

\author{
Chaitanya Dosakayala \\ Department of Aerospace Engineering \\ Alliance College of Engineering and Design \\ Alliance University \\ Bangalore, Karnataka, INDIA
}

\begin{abstract}
The objective of this study is to know the moisture absorption rate and its behavior (Swelling) of the Activated Carbon Reinforced Polymer Composite when it is subjected to mineral water, saline water, and moist soil environments. The composite is made up of activated carbon (reinforcement) that is taken by $1 \%, 2 \%$, and $3 \%$ against the weight of composite material. The epoxy is taken in a separate beaker by weights of $99 \%, 98 \%$, and $97 \%$ to that of the composite material, and about $10 \%$ (of epoxy) hardener is added and stirred mechanically, after a while the activated carbon is added slowly and gently stirred until a fine mixture is obtained. The mixture is now poured into a rectangular silicone mold, and is now left alone to cure under standard atmospheric conditions for 2 days. The solid particle erosion behavior of carbon and the reinforced epoxy composite has been characterized. The erosive wear of these composites has been evaluated at different impingement angles.
\end{abstract}

\section{INTRODUCTION}

Although mechanical testing of polymer matrix composites (PMCs) is most commonly performed in ambient laboratory conditions, additional testing is often performed in other environmental conditions to determine properties of interest. Additional test environments typically include higher or lower test temperatures as well as elevated levels of moisture in the environment. The selection of these environmental conditions for testing is based on established limits of

\author{
Sindhu Kamat \\ Department of Aerospace Engineering \\ Alliance College of Engineering and Design \\ Alliance University \\ Bangalore, Karnataka, INDIA \\ Vijayalakshmi Bharathi K \\ Department of Aerospace Engineering \\ Alliance College of Engineering and Design \\ Alliance University \\ Bangalore, Karnataka, INDIA
}

the composite material's usage as well as the environmental conditions expected in service.

In general, the mechanical properties of PMCs can be affected significantly by exposure to elevated temperatures. However, the combination of elevated temperature and moisture, referred to as hot/wet conditions, often produces the most critical environmental conditions for which the most severe reductions are produced in several important mechanical properties.

At ambient temperature, a PMC can take months or years to reach this "wet" condition, defined as a state of moisture equilibrium throughout its thickness. Since moisture diffusion rates increase significantly with temperature, composite test specimens may be moisture conditioned in shorter times at elevated temperatures. However, there are limits on the moisture-conditioning temperature, as excessive conditioning temperatures can produce property changes in the polymer matrix that are not representative of moisture conditioning at ambient humid conditions. For example, the Composite Materials Handbook (CMH-17) suggests a maximum conditioning temperature of $82^{\circ} \mathrm{C} / 180^{\circ} \mathrm{F}$ for epoxybased composites cured at $177^{\circ} \mathrm{C} / 350^{\circ} \mathrm{F}$. For lowertemperature-cure epoxies, lower conditioning temperatures are suggested. As described in ASTM D52294, there is no specified time for moisture conditioning, as moisture equilibrium is established by the mass of the specimen changing by less than 0.02 percent between successive measurements. Further, the use of pressurized steam or water immersion are discouraged, as they do not produce the same state of 
moisture saturation as would occur at ambient temperatures with humid air and do not produce significant reductions in conditioning time. If solid particles impinge against a target surface and because of local damage combined with material removal, this kind of wear is generally referred to as erosion. Polymer composite materials have generated wide interest in various engineering fields, particularly in aerospace applications, because they exhibit high specific strength and stiffness as compared to monolithic metal alloys. Polymer composite materials are therefore finding increased application under conditions in which they may be subjected to solid particle erosion. Examples of such applications are pipe line carrying sand slurries in petroleum refining, helicopter rotor blades pump impeller blades, high speed vehicles and aircraft operating in desert environments, water turbines, and aircraft engine blades.

\section{MATERIALS AND METHODS}

\section{Raw Materials}

Following are the list of materials used for the preparation of Activated Carbon Reinforced Epoxy Polymer Composite

1) Epoxy resin, LY 556.

2) Hardener, HY 951.

3) Activated carbon powder.

\subsection{Epoxy resin}

Epoxy LY556 [liquid di glycidyl ether of biphenol -A (DGEB-A)] resin is used for this experimental study. It is being used extensively because of its properties such as high strength, best adhesion property, excellent performance and good chemical resistance at higher temperatures. Epoxy resin density, equivalent weight, and viscosity are $1.2 \mathrm{~g} / \mathrm{cm} 3,182$ 192 (gr/eq) and $11000-14000 \mathrm{MPa}$ at $25^{\circ} \mathrm{C}$ respectively. [5-2006]

\subsection{Hardener}

The curing agent for the Epoxy resin LY 556 is the epoxy hardener HY-951 [NN0 (2-amineethylethane-1, 2- diamine)]. It can also be used with epoxy resin with an amine value of 260-284 (mg KOH gm-1). Both the epoxy resin and curing agent were obtained from a supplier. [4-2007]

\subsection{Activated carbon powder}

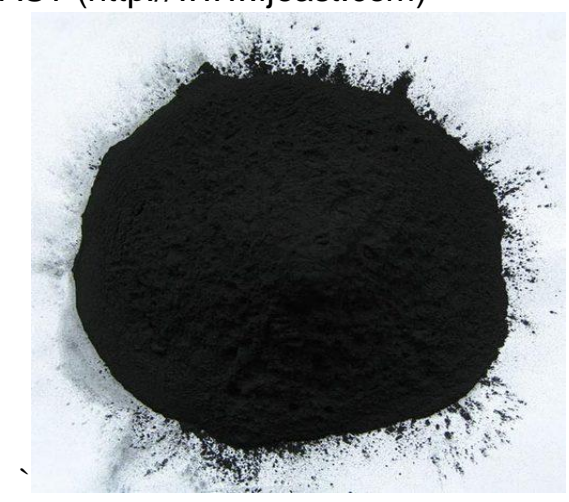

Fig 1. Activated carbon powder [8]

Activated charcoal is a fine, odorless, black powder. Its toxin-absorbing properties have a wide range of medicinal and cosmetic uses. The manufacture of activated charcoal makes it extremely absorbent, allowing it to bind to molecules, ions, or atoms. In this way, it removes the toxic molecules from dissolved substances thoroughly and is scientifically proven. Activated carbon powder density is $1.45 \mathrm{~g} / \mathrm{cm} 3$. [3-2006]

\section{Mold Fabrication}

A glass slab of dimensions $20 \mathrm{~cm} * 16 \mathrm{~cm}$ is taken and is placed in a plastic frame having a flat internal surface. Now the 2part silicon is mixed thoroughly and vacuumed to remove any air bubbles, then the silicon mixture is poured into the plastic frame from the edge of the glass. The mold is left alone to harden for a day. After a day the silicon fix was removed from the plastic frame and the glass slab was removed. The interior of the fix is cleaned with cotton and acetone.

\section{Composite Slab Fabrication}

The Hand Lay-up process was used to fabricate the Activated Carbon Reinforced Epoxy Composite [62015]. The mold releasing agent is sprayed on the internal surface of the mold, then the volume of the rectangular mold is calculated by using the formula

$$
V=l * b * h
$$

Where,

"V" is the volume, "l" is the length, "b" is the breadth and " $\mathrm{h}$ " is the height.

The volume of the mold is the entire volume of the composite, with the help of the volume of the composite, the volume of the constituent elements, the reinforcement, and the matrix volume are calculated. 
International Journal of Engineering Applied Sciences and Technology, 2020

Vol. 4, Issue 9, ISSN No. 2455-2143, Pages 186-193

Published Online January 2020 in IJEAST (http://www.ijeast.com)

The volume of the reinforcement is kept constant and now the volume of the matrix is calculated, by using the relation between density and volume the mass of the constituent elements, matrix, and reinforcement are calculated.

$$
\operatorname{Density}\left(\mathrm{gm}^{\mathrm{cm}} \mathrm{cm}^{3}\right)=\rho=\frac{\operatorname{mass}(\mathrm{gm})}{\operatorname{volume}\left(\mathrm{cm}^{3}\right)}=\frac{m}{v}
$$

The mass of each constituent element, matrix and reinforcement are weighed correctly with the help of weighing machine and then taken in separate beakers, now in another beaker, 10 percent of the hardener is taken against the weight of the epoxy resin since it's the optimal mixing combination

The epoxy and hardener are mixed thoroughly until a uniform mixture is obtained, Now the activated carbon is poured into the mixture of epoxy and hardener slowly little by little and continuously stirred. The mixture of all the elements epoxy resin, epoxy hardener, and activated carbon is stirred continuously until the reaction starts and the mixture starts to liberate heat.

The mold is placed over a flat surface and then the mixture is poured into the mold, the mixture is now allowed to settle for an entire time period of 48 hours.

After 48 hours the component will be removed from the silicon mold, at this time the mixture will be hardened completely, the component is now cut into pieces of size $2 * 2 \mathrm{~cm}$ with the help of an electrical blade.

Samples of $1 \%, 2 \%, 3 \%$ activated carbon reinforced epoxy composite are crafted and from each component 12 samples are made.

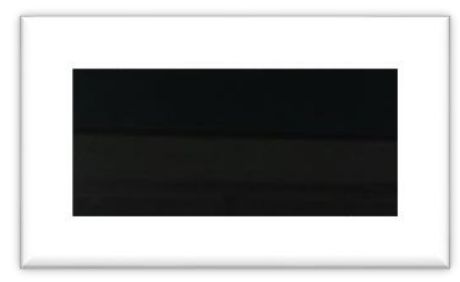

Fig 2. Composite mixture poured into the mold.

\section{ENVIRONMENTAL TEST}

\subsection{THICKNESS SWELL AND MOISTURE ABSORPTION TEST:}

The pieces are labeled and the mean thickness, weight of each individual piece are tabulated. The pieces are placed under three different environmental conditions - "Mineral Water", "Saline Water" and "Moist Soil". After every 24 hours the pieces are removed from the medium, cleaned and measured again for weight and mean thickness, and then paced back in the medium. This is repeated for consecutive 10 days. The environmental tests were performed at conditions $1 \mathrm{~atm}$ pressure and 297K temperature. [12015], [2-2010]

$$
\begin{gathered}
\text { Moisture Absorption }=\frac{M_{T}-M_{I}}{M_{I}} * 100 \\
\text { Thickness Swell }=\frac{T_{T}-T_{I}}{T_{I}} * 100
\end{gathered}
$$

Where,

$M_{T}$ and $T_{T}$ are the mass and thickness of the composite after a certain time of subjecting to environmental conditions.

$M_{I}$ and $T_{I}$ are the mass and thickness of the composite before subjecting to the environmental conditions.

\subsection{EROSION WEAR TEST RIG}

The erosion test over the specimens was performed at room temperature.

The carbon composite that has undergone the moisture absorption by placing in the various environmental condition is taken to perform erosion tests. The tests are performed at standard atmospheric pressure of $1 \mathrm{~atm}$ and temperature of $297 \mathrm{~K}$ for the various percentage of carbon and at different orientation angles. Before placing the specimen in test rig the initial weight of the specimen is noted down. The specimen is placed in the test rig at an angle $\left(90^{\circ}, 60^{\circ}, 45^{\circ}\right.$, and $\left.30^{\circ}\right)$. The speed of the disk is kept at $0.6 \mathrm{rpm}$ and each specimen is placed inside for 10 minutes. The sand particles fall on the specimen and erode the surface material for 10 minutes. The specimen is now removed, cleaned and weighed. The variations in the weight of different samples for different orientations have been plotted and the results are analyzed. [7-1990] 


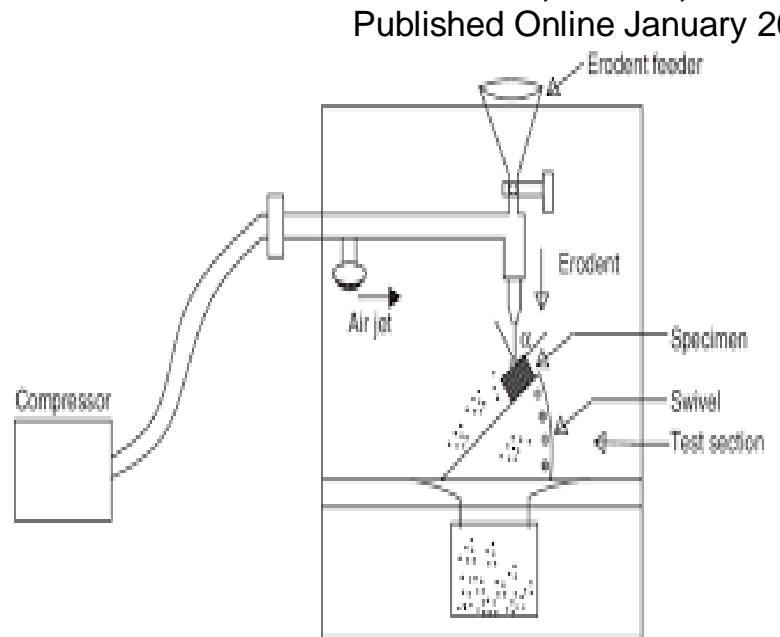

Fig 3. Erosion wear test rig [9]

\section{RESULTS AND DISCUSSION}

\subsection{Moisture absorption}

Figure.4.1.1, 4.1.2 and 4.1.3 shows the moisture absorption of $1 \%, 2 \%, 3 \%$ activated carbon reinforced composite with exposure time (days) in mineral water, saline water, moist soil environment.

It is found that the specimens placed in mineral water and saline water environment, the percentage of moisture absorption is very high, initially increased with exposure time and as the exposure time increases the percentage of moisture absorption came to a standard state; whereas the specimens placed in moist soil environment show a gradual increase in the moisture absorption, and as the exposure time increases there is no change in the weight as the specimens have achieved the saturation state.

The reason for moisture adsorption can be explained by one of the main theories i.e. Water adsorption occurs according to the Dubinin-Serpinsky mechanisms involving clustering around primary adsorption centers. In this mechanism, it is assumed that water adsorption occurs through the formation of clusters of chemisorbed water at active sites that are present on the carbon surface (surface groups), followed by the growth and coalescence of these clusters. [2-2010]

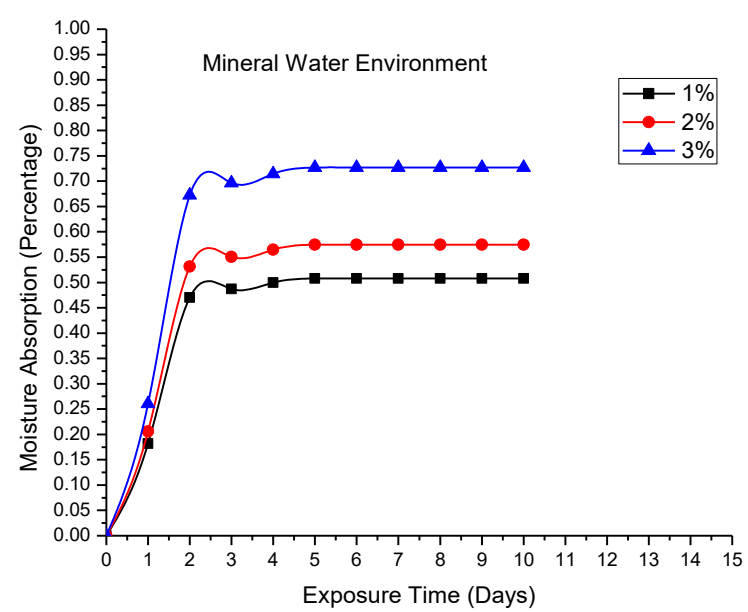

Fig.4.1.1

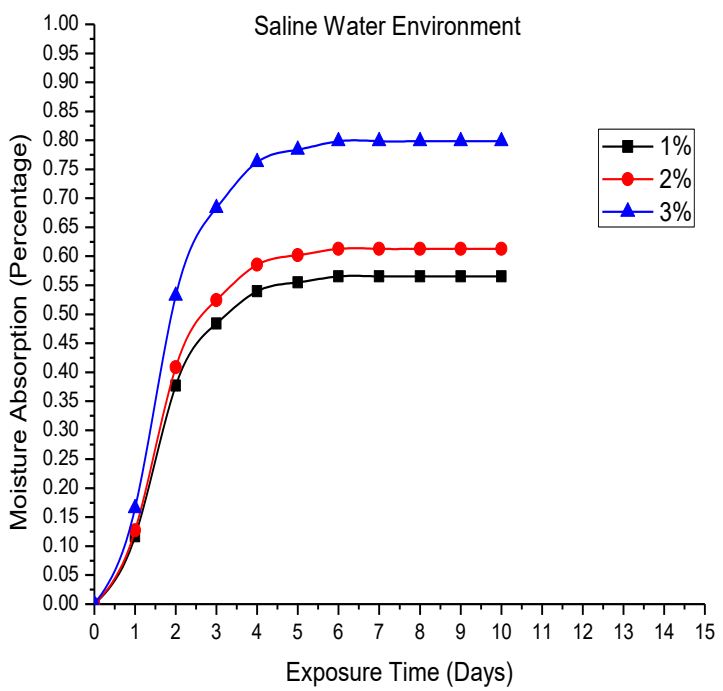

Fig.4.1.2 


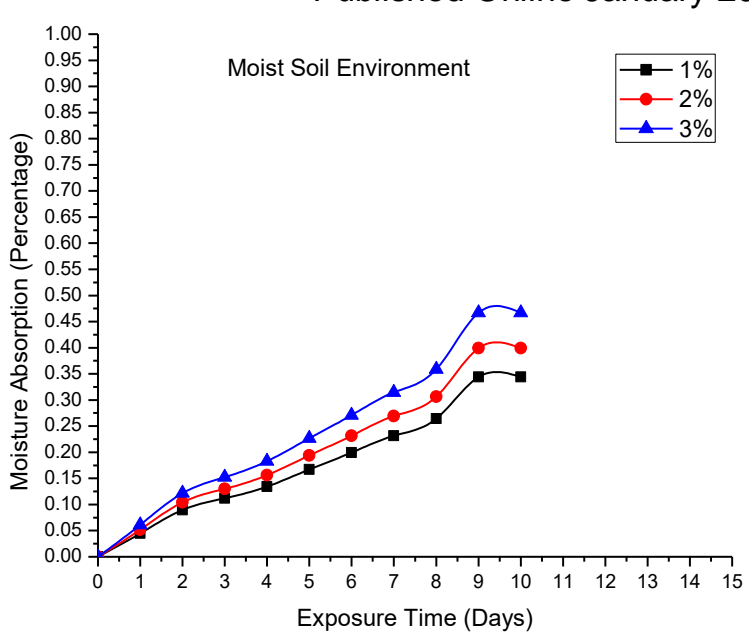

Fig.4.1.3

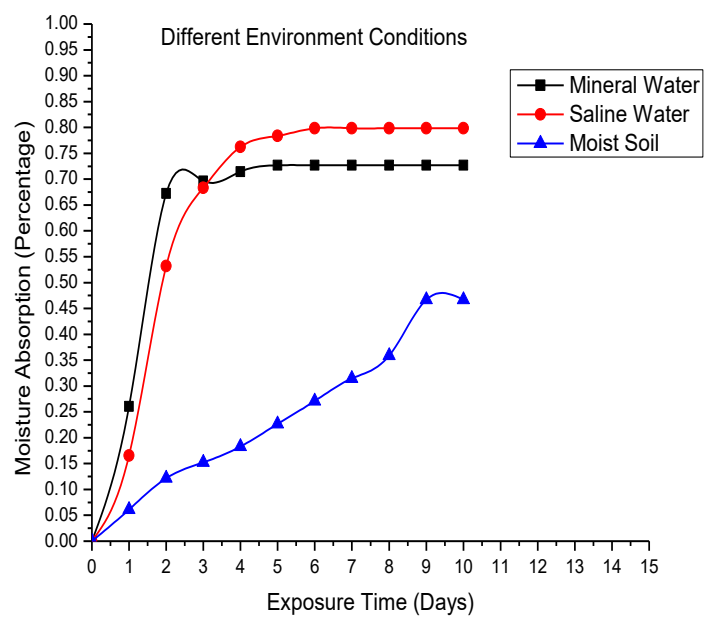

Fig.4.1.4

It is also found that moisture absorption of $3 \%$ activated carbon reinforced composite is more followed by $2 \%$ and $1 \%$. Fig. 4.1 .4 compares the moisture absorption of $3 \%$ reinforced activated carbon composite in mineral water, saline water, and moist soil at different exposure times. It is found that in saline water moisture absorption is more followed by mineral water and then moist soil. This may be due to the absorption of salts by activated carbon from saline water. Hence activated carbon is used to reduce around $60 \%$ of the salts from seawater.

\subsection{Thickness swell}

Fig.4.2.1, 4.2.2 and 4.2.3 shows the variation in thickness of $1 \%, 2 \%$, and $3 \%$ activated carbonreinforced polymer composite with exposure time in mineral water, saline water, and moist soil environment.

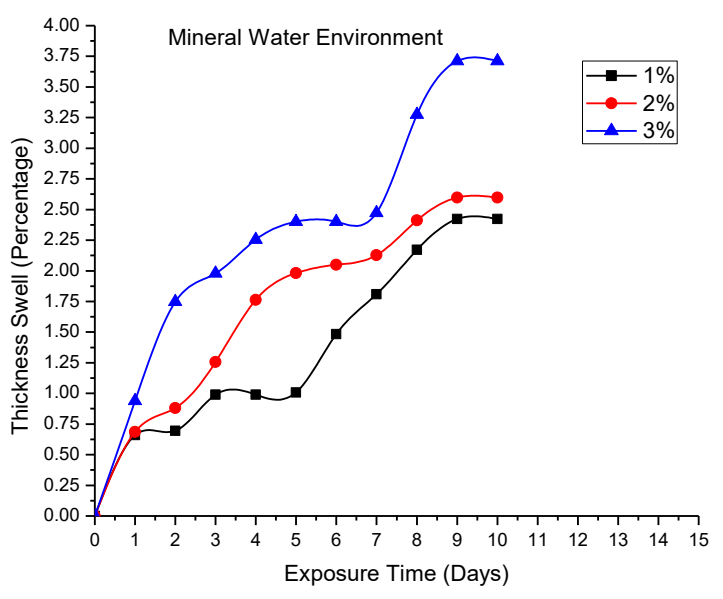

Fig.4.2.1

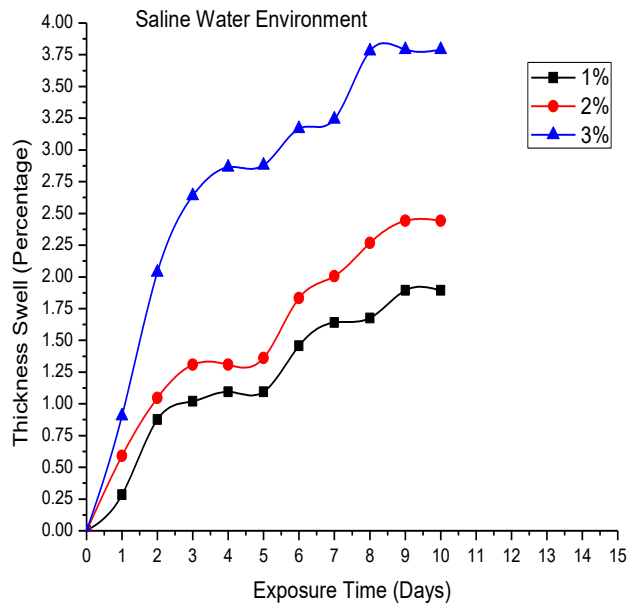

Fig.4.2.2

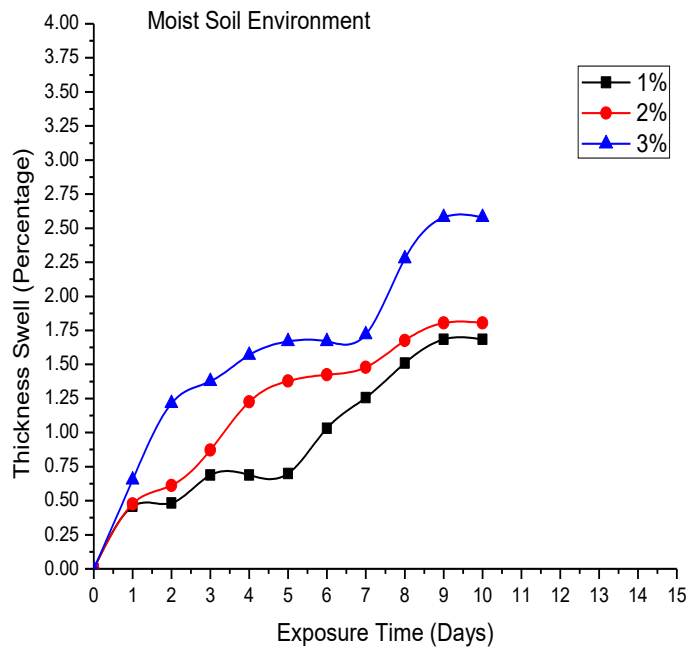


International Journal of Engineering Applied Sciences and Technology, 2020

Vol. 4, Issue 9, ISSN No. 2455-2143, Pages 186-193

Published Online January 2020 in IJEAST (http://www.ijeast.com)

Fig.4.2.3

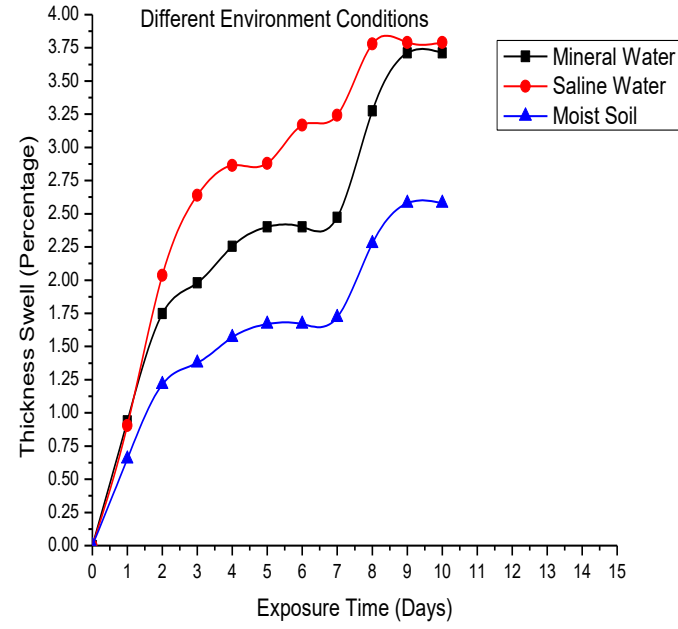

Fig.4.2.4

It is found that thickness swell increases with an increase in exposure time in all three environments but gradually. It constantly increases with time. It is further found that thickness swell is more in 3\% activated carbon reinforced composite followed by $2 \%$ and $1 \%$. The reason may be due to more moisture absorption of $3 \%$ composite specimens. Fig. 4.2.4 compares the thickness swell of 3\% activated carbon reinforced composite specimens placed in mineral water, saline water, and moist soil at different exposure times. It is observed that initially the thickness swelling in saline water and mineral water is almost the same for the exposure time of around 36 hours but after that, the thickness swelling shown by saline water samples increased rapidly compared to mineral water specimens. Least swelling was shown by samples placed in moist soil environment compared to others.

\subsection{Erosion Rate}

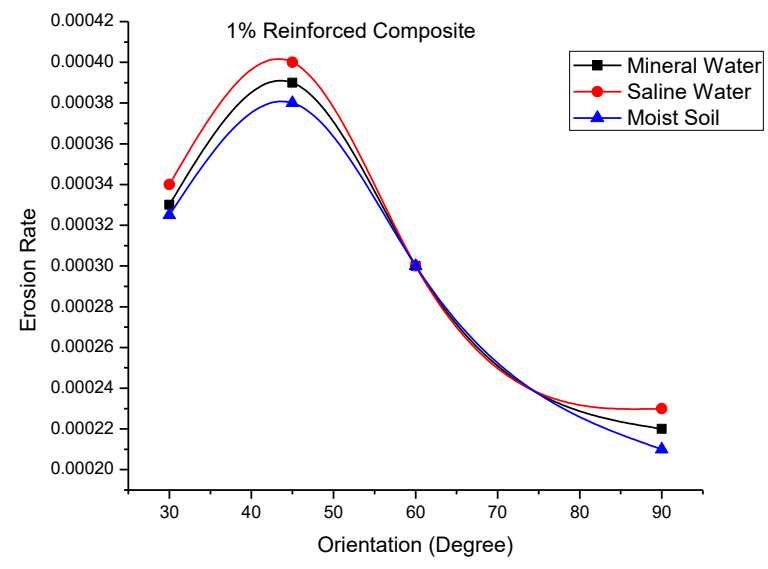

Fig.4.3.1

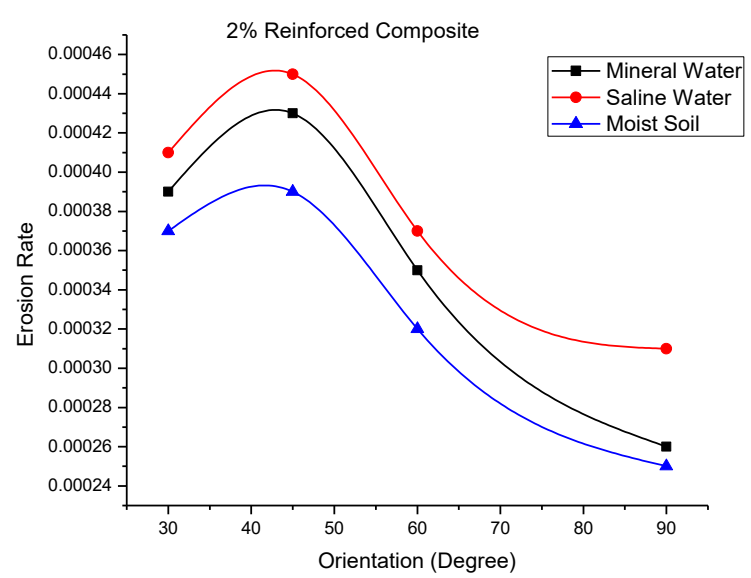

Fig.4.3.2 
International Journal of Engineering Applied Sciences and Technology, 2020

Vol. 4, Issue 9, ISSN No. 2455-2143, Pages 186-193

Published Online January 2020 in IJEAST (http://www.ijeast.com)

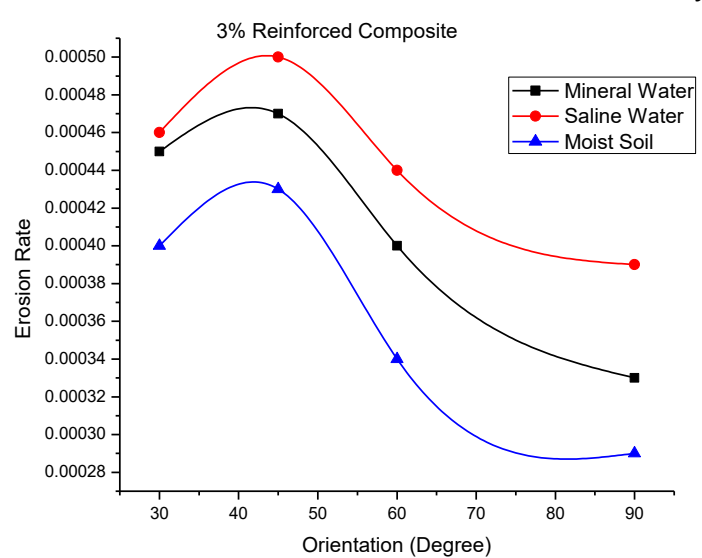

Fig.4.3.3

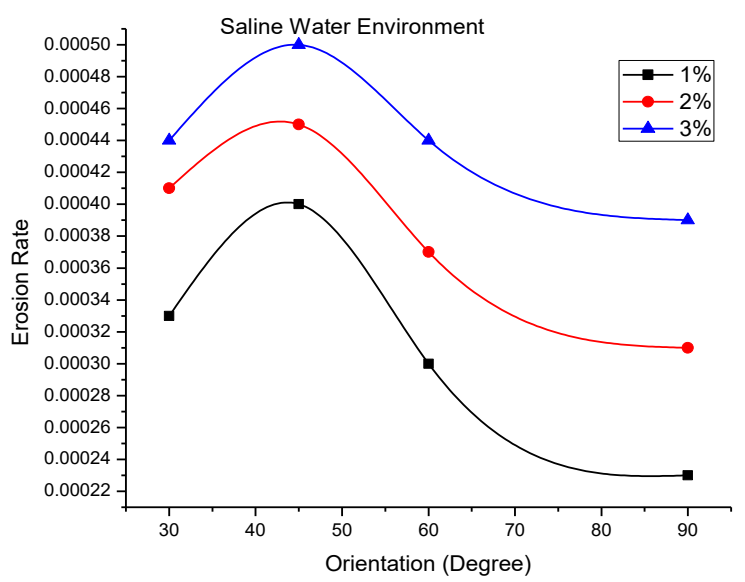

Fig.4.3.4

Fig.4.3.1, 4.3.2 and 4.3.3 represent the erosion rate of composite (placed for 10 days in the mineral water, saline water, and moist soil environment) with the orientation of flow.

It is found that erosion rate increases as the orientation increase till 45 degrees and beyond this angle, the erosion rate of the composite decreased. It is further found that the specimens placed in saline water showed more erosion rate followed by mineral water and then moist soil. The reason may be due to more moisture absorption of specimens placed in saline water. Fig. 4.3.4 compares the erosion rate of $1 \%, 2 \%, 3 \%$ activated carbon reinforced composite placed in saline water. It is observed that the erosion rate shown by the $3 \%$ reinforced specimen is more than $2 \%$ followed by $1 \%$, this may be due to the increased thickness swell as the reinforcement increased.

\section{CONCLUSION}

From this study, the following conclusions can be drawn

1. By exposing activated carbon reinforced composite to mineral water, saline water, and moist soil environment, moisture absorption and thickness swell occurred with time.

2. As the percentage of reinforcement increased moisture absorption, thickness swell, erosion rate increased.

3. The tendency to absorb water is more in activated carbon than the epoxy resin.

4. Thickness swell, moisture absorption, and erosion rate are more in saline water compared to mineral water and moist soil environment.

5. The maximum erosion rate of the activated carbonreinforced composite occurs when it is at a 45-degree orientation to the flow.

6. As the concentration of activated carbon in the composite increases, the hardness of the composite decreases.

7. Even after the moisture absorption attained the saturation state, the thickness swell still kept on increasing.

8. Below or after 45 degrees the erosion rate decreased.

\section{REFERENCES}

[1] E.Munoz, J.A.Garcia-Manrique, (12 August 2015). "Water Absorption Behaviour and Its Effect on the Mechanical Properties of Flax Fibre Reinforced Bioepoxy Composites", International Journal of Polymer Science, (Pg1-10).

[2] Ali Reza Shakeri, Ali Ghasemian, (April 2010). "Water Absorption and Thickness Swelling Behaviour of Polypropylene Reinforced with Hybrid Recycled Newspaper and Glass Fiber", Research Gate, (Pg183193)

[3] Harry Marsh, Francisco Rodriguez-Reinoso (2006). "Activated Carbon First Edition", ELSEVIER, (Pg1-112)

[4] Ch.Jochum, J.C. Grandidier, M.A. Smaali, (September 2007). "Experimental study of long T300 carbon fibre undulations during the curing of LY556 epoxy resin", ELSEVIER, (Pg2633-2642)

[5] B. Suresha, G. Chandramohan, P. Samapthkumaran, S.Seetharamu, S.Vynatheya, (May 2006) "Friction and Wear Characteristics of Carbon- 
epoxy and Glass-epoxy Woven Roving Fiber Composites", Journal of Reinforced Plastics and Composites, $(\mathrm{Pp} 87-101)$

[6] M. Elikington, D. Bloom, C. Ward, A. Chatzimichali, K. Potter, (2 May 2015). "Hand layup: understanding the manual process", Advanced Manufacturing: Polymer \& Composites Science, $(\operatorname{Pg} 138-151)$

[7] J.B.Zu, I.M. Hutchings, G.T. Burstein, (November 1990) "Design of a slurry erosion test rig", Elsevier, Wear, (Pg331-344)

[8] Activated Carbon Powder Image, Source-Google, "https://www.indiamart.com/proddetail/activatedcarbon-powder-15196800548.html".

[9] Erosion Test Rig, Source-Google, "https://www.researchgate.net/figure/A-schematicdiagram-of-the-erosion-test-rig fig1_251962231".

[10] Philip M. Edwards, (August 2002). "Origin 7.0: Scientific Graphing and Data Analysis Software", Journal of Chemical Information and Computer Sciences, $(\operatorname{Pg} 1270-1310)$

[11] R.S. Lakes, S. Kose, H. Bahia, (DOI: 10.1115/1.1448923) "Analysis of High-Volume Fraction Irregular Particulate Damping Composites", Academia, (Pg174-177)

[12] Aleksander Muc, Marek Barski, (3 February 2018) "Design of Particulate-Reinforced Composite Materials", MDPI, (Pg1-20) 